\title{
Spinal reflexes and the concentrations of 5-HIAA, MHPG, and HVA in lumbar cerebrospinal fluid after spinal lesions in man
}

\author{
P. ASHBY ${ }^{1}$, M. VERRIER, J. J. WARSH, AND K. S. PRICE \\ From the University of Toronto, Toronto, Canada
}

SYNOPSIS Descending bulbospinal pathways that employ specific neurotransmitter substances are known to be capable of modulating segmental reflex activity in the experimental animal. To determine whether this might also occur in man correlations have been sought between the activity in spinal reflex pathways and the lumbar cerebrospinal fluid (CSF) concentrations of 5-hydroxyindolacetic acid (5-HIAA), 3 methoxy-4-hydroxyphenylglycol (MHPG), and homovanillic acid (HVA) in 12 patients with complete or virtually complete spinal lesions. The concentrations of 5-HIAA and MHPG in lumbar CSF are reduced after complete or virtually complete spinal lesions in man. This may occur within 18 days of the lesion. MHPG concentrations appear to be inversely related to the level of the lesion. The HVA concentration in lumbar CSF is reduced when there is obstruction of the CSF pathways. No relationship could be demonstrated between the concentrations of 5-HIAA or MHPG in lumbar CSF and the activity in the spinal monosynaptic pathway (estimated from the proportion of the motoneurone pool activated by the Achilles tendon reflex or $\mathrm{H}$ reflex) or the activity of a spinal inhibitory mechanism (estimated by the degree of vibratory inhibition of the monosynaptic reflex). Patients with a tonic vibration reflex (TVR) tended to have higher MHPG levels. There appeared to be an association between low CSF HVA and enhanced vibratory inhibition of the monosynaptic reflex in the nine patients whose spinal lesions were complete.

In the mammalian nervous system there are a number of bulbospinal pathways capable of modulating spinal reflex activity. Some of these pathways employ specific neurotransmitter substances. For example, there is a system of noradrenergic fibres and a system of serotonergic fibres, both descending in the ventrolateral columns to terminate in the spinal grey matter. The cell bodies of these neurones are all in the brain stem and there are no adrenergic or serotonergic cell bodies at spinal level (Dahlström and Fuxe, 1965). There are probably no dopaminergic neurones or terminals in the spinal cord (Andén, 1965; Hillarp et al., 1966).

The alterations in spinal reflexes that are observed when L-dopa is administered to a spinal cat are considered to be due to the release of noradrenaline at spinal terminals (Andén et al., 1966a; Jurna and

1 Address for correspondence: P. Ashby, Toronto Western Hospital, 399 Bathurst Street, Toronto, Ontario M5T 2S3, Canada.

(Accepted 22 June 1976.)
Lundberg, 1968). The release of noradrenaline appears to inhibit a short latency flexion reflex pathway, facilitate a more physiological long latency flexion reflex, produce alterations in primary afferent depolarisation (presynaptic inhibition) and enhance fusimotor drive and the excitability of the monosynaptic reflex (Andén et al., 1966b,c; Bergmans and Grillner, 1969; Grillner, 1969; Baker and Anderson, 1970). The release of serotonin (5HT) has similar, but distinct, effects which include a greater degree of facilitation of motoneurones (Andén et al., 1964a; Ahlman et al., 1971; Anderson, 1972; Ellaway and Trott, 1975a,b). The modulation of segmental reflexes by these descending neurotransmitter-specific pathways is evidently important. If the descending noradrenergic pathway is activated in the spinal cat and the animal is placed on a treadmill it will exhibit stepping movements (Grillner, 1973). There is histological evidence suggesting that similar systems of neurotransmitter-specific pathways exist in man (Nobin and Björklund, 1973; Olson et al., 1973). 
There are, as yet, no neurophysiological studies on spinal man to indicate whether they serve a similar function.

It has become clear that the concentrations of 5-HIAA and MHPG in lumbar CSF may reflect predominantly the local spinal metabolism of serotonin and noradrenaline (especially if mixing of CSF is prevented), whereas CSF HVA is principally derived from dopamine metabolism by higher centres (Garelis et al., 1974; Curzon, 1975). The concentrations of these monoamine metabolites in unmixed lumbar CSF may therefore provide an indication of the activity of these descending noradrenergic and serotonergic systems. Spinal lesions which interrupt these pathways are known to produce alterations in the lumbar CSF concentrations of these amines in man (Post et al., 1973; Johansson and Roos, 1974).

Spinal lesions also result in alterations in spinal reflex activity in man. Some of these reflex changes can be documented by neurophysiological tests. For example, there is evidence for a reduction (Weaver et al., 1963) and then an increase (Dietrichson, 1973) in fusimotor drive; an increase (Ashby and Verrier, 1975) and then a failure (Delwaide, 1973) of a spinal inhibitory mechanism (that may be presynaptic), and loss of transmission in the polysynaptic pathway responsible for the tonic vibration reflex (Lance et al., 1973).

The concomitant alterations in spinal reflexes and in lumbar CSF neurotransmitter metabolites provide an opportunity to explore the relationship between spinal reflex activity and neurotransmitters in man.

In this study the activity of the monosynaptic reflex, the state of fusimotor drive, the activity of a polysynaptic reflex pathway, and of a spinal inhibitory mechanism have been examined in patients with severe or complete spinal lesions. These measurements have been combined with estimations of MHPG, 5-HIAA and HVA in lumbar CSF. Precautions were taken to minimise the degree of intermixing of lumbar and cisternal CSF.

\section{METHODS}

Patients with 'complete' spinal lesions volunteered for the study and provided written and informed consent after a full explanation. Two patients were rejected because their ankle jerks were unobtainable. Twelve patients were accepted into the study. The lesions resulted from trauma except in case 9 where quadriplegia followed laminectomy. A complete neurological examination was carried out on each patient and the following protocol initiated. Three days before the study all drugs (except enemas and laxatives) were stopped and the diet started. The basic diet was that used before VMA studies (with the exclusion of vanilla, bananas, coffee, tea, cola, cheese, chocolate, wine, beer, orange and pineapple or their juices) with the additional restriction of serotonincontaining foods (tomatoes, plums, avocado, and egg plant). The dietary tryptophan was kept constant at $900 \mathrm{mg}$ daily. Over the three day preparatory period the patients had their normal exercise or physiotherapy. The night before the study the patient had 12 hours of bed rest. At 0830 on the day of the study, with the patient fasting, the lumbar puncture was performed. Every effort was made to avoid CSF mixing. The patient was instructed not to cough or to make any exertion and was turned to one side gently so as to avoid flexor spasms. The lumbar puncture was performed at the L4-5 interspace. Local anaesthetic was not required. The opening pressure was recorded and a Queckenstedt test performed by compression of the neck veins. A rise of less than $30 \mathrm{~mm}$ of water was taken as evidence of obstruction of CSF pathways. Standard aliquots of CSF were collected in clean, sterile, graduated tubes. The first $2 \mathrm{ml}$ were used for the cell count and for the protein estimation. The subsequent $12 \mathrm{ml}$ (except in two cases (6 and 7) where only an additional $8 \mathrm{ml}$ could be obtained) were used for estimation of MHPG, 5-HIAA, and HVA. The cell count was carried out on the first sample within 10 minutes of the lumbar puncture. Two millilitres of the second sample were separated for the MHPG estimation and the remaining $10 \mathrm{ml}$ acidified with 50-100 $\mu$ l concentrated hydrochloric acid $(\mathrm{HCl})$. Both specimens were then frozen within 30 minutes of the lumbar puncture at $-20^{\circ} \mathrm{C}$. The patients meanwhile had breakfast. Blood was with-? drawn for the estimation of serum diazepam in those patients who had been taking this substance in high doses and neurophysiological studies were then performed, within two to four hours of the lumbar puncture, using the methods described by Ashby and Verrier (1975).

The neurophysiological studies have been interpreted as follows. The compound action potential of the soleus muscle resulting from supramaximal electrical stimulation of the popliteal nerve ( $M$ response) was assumed to represent the activity of $100 \%$ of the soleus motor units. The proportions of this motoneurone pool that could be activated by the $\mathrm{H}$ reflex $(\mathrm{H} / \mathrm{M}$ ratio) or Achilles tendon reflex (ATR/M ratio) were used as estimates of the excitability of the monosynaptic reflex arc. A comparison of these two ratios was used as an indication of the state of fusimotor drive. The peak tension resulting from supramaximal electrical stimulation of the popliteal nerve was assumed to represent the activity of $100 \%$ of soleus motor units. By comparing this value with the tension produced by the TVR, the TVR could also be expressed as a proportion of the 
motoneurone pool reflexly activated (TVR/M ratio). The ratio of the maximum $\mathrm{H}$ reflex (vibration) to the maximum $\mathrm{H}$ reflex (control) was used as a measure of a spinal inhibitory mechanism that may be presynaptic (Delwaide, 1973).

CSF protein was estimated by the method of Meulemans (1960). A $1.0 \mathrm{ml}$ sample of the CSF was added to a mixture of $3 \%$ sulphosalicylic acid and $7 \%$ sodium sulphate and the degree of turbidity determined using a spectrophotometer at $660 \mathrm{~m} \mu$.

5-HIAA was determined using the technique of Giacalone and Valzelli (1966) as modified by Lloyd et al. (1974). All values were compared with a recovery sample of 200 ng 5-HIAA (Aldrich Chemical Company). Immediately after reading, the sample was treated with a few drops of $10 \%$ hydrogen peroxide to ensure that the fluorescence was not attributable to aspirin (all of the samples from the patients with spinal lesions were negative).

HVA was assayed in $0.5 \mathrm{ml}$ samples of CSF by a modification of the procedure of Watson et al. (1974). Twenty nanograms of HVA- $a-D_{2}$ (Merck, Sharp, and Dohme, Canada Ltd) was added to all samples and standards as an internal standard.

Total MHPG was assayed by a modification of the procedure of Bond (1972). One millilitre of CSF was hydrolysed enzymatically at pH 5.8 for 16-20 hours at $39^{\circ} \mathrm{C}$ in the presence of Helix pomatia sulphatase, type H-1 (Sigma Chemical Company; 18600 units/g). Samples of CSF were adjusted to pH 10-10.5 with $1 \mathrm{M}$ sodium bicarbonate buffer and $1 \mathrm{~N} \mathrm{NaOH}$. MHPG was acetylated and extracted by shaking the aqueous solution with $10 \mathrm{ml}$ diethyl ether containing $1 \%$ acetic anhydride. The ether content was removed and dried over sodium sulphate and evaporated to dryness under $\mathrm{N}_{2}$ in $1 \mathrm{ml}$ reaction vials. The residue was reacted with trifluoracetic anhydride in ethyl acetate $(1: 5)$ for 60 minutes at room temperature. The reagents were then evaporated to dryness under $\mathrm{N}_{2}$ and the reaction products reconstituted in $25 \mu \mathrm{l}$ dry ethyl acetate. MHPG-methoxy-[14C] was used as an internal standard. The latter was prepared as described by Gordon et al. (1974). Samples were analysed on a Finnigan 3200 GC-MS system using multiple ion monitoring. The HVA derivative was detected using the prominent ions which occurred at 460 and $283 \mathrm{amu}$. For the HVA- $\alpha-\mathrm{D}_{2}$ derivative the respective ions were monitored at 462 and $285 \mathrm{amu}$. Quantitation of HVA in CSF was performed by generating standard curves of the fragment ratios for HVA/HVA- $\alpha-D_{2}$ versus concentration. The MHPG derivative gives prominent ions at 376 and $249 \mathrm{amu}$ respectively, while for the ${ }^{14} \mathrm{C}-\mathrm{MHPG}$ derivative the major ions monitored occurred at 378 and 251 amu. Quantitation of MHPG in CSF samples was per- formed using standard curves of the MHPG/ MHPG- $\left[{ }^{14} \mathrm{C}\right]$ ratio versus concentration.

'Control' CSF was obtained from patients undergoing myelography who had either a normal neurological examination or only a minimal neurological deficit. Normal subjects acted as controls for the neurophysiological studies. Student's $t$ test and the correlation coefficient were used in statistical analysis. Probabilities of less than 0.05 (two tailed) were considered significant.

\section{RESULTS}

\section{PHYSICAL FINDINGS}

In nine of the patients the spinal lesion was physiologically complete (in no instance was there surgical confirmation that the lesion was anatomically complete). In the remaining three patients the neurological examination indicated that there was sparing of some long tracts. One patient (case 2) was found to have partial preservation of pin prick perception below T7 dermatome and the ability to make perceptible movements in one leg; another (case 12) had early development of powerful extensor spasms; a third (case 9) subsequently developed the ability to make movements of one toe. These three patients were therefore labelled 'virtually complete'. All three had prominent extensor spasms. The serum diazepam level was estimated at the time of the electrophysiological examination in five patients who had been taking large quantities of the drug. In spite of a three day washout period diazepam was detectable in the serum of case 4 $(0.17 \mu \mathrm{g} / \mathrm{ml})$ and case $6(0.25 \mu \mathrm{g} / \mathrm{ml})$.

\section{ELECTROPHYSIOLOGICAL STUDIES}

The patients were part of a larger group whose neurophysiological findings have been reported previously (Ashby and Verrier, 1975). The reflex abnormalities in the present group reflect, in general, the findings of that study. Thus the tonic vibration reflex was absent in all of those patients with physiologically complete spinal lesions and the $\mathrm{H}$ vibration/ $\mathrm{H}$ control ratio was low when the lesion was recent (especially if it was complete). The present group, however, included three patients who had a low $\mathrm{H}$ vibration/ $\mathrm{H}$ control ratio, although they had lesions of long duration. This was considered to be contrary to the general trend for this ratio to increase with elapsed time.

\section{OBSTRUCTION OF CSF PATHWAYS}

A rise in pressure of less than $30 \mathrm{~mm}$ of water during the Queckenstedt test and a CSF protein of more than $0.5 \mathrm{~g} / 1$ were considered to indicate obstruction of the CSF pathways. By these criteria three patients had complete obstruction of the CSF pathways (Table). 


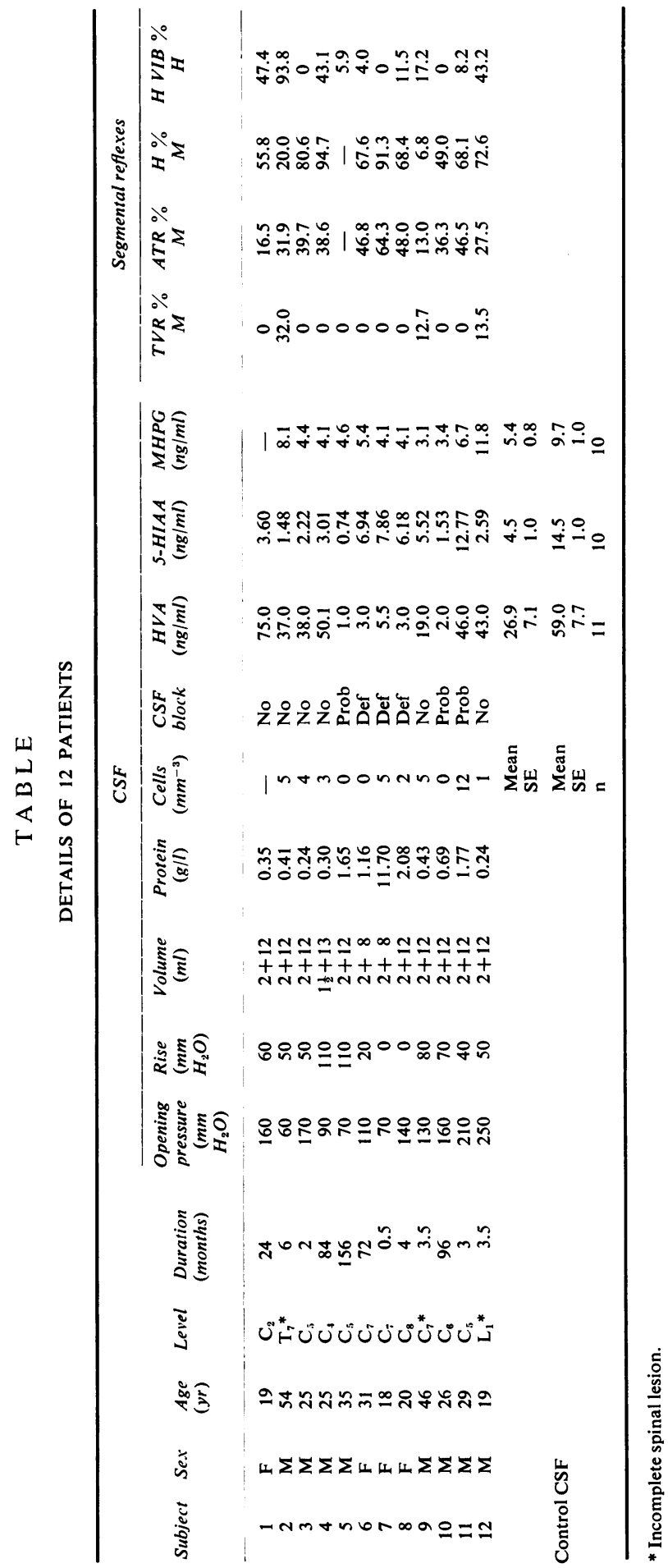


Another three patients had a raised CSF protein (in two instances many years after the accident) but had an apparently normal Queckenstedt test. For the purpose of analysis these patients were included in the 'obstructed' group but they are designated separately in the figures. The remaining six patients had no evidence of obstruction of the CSF pathways by these criteria. Only one patient had had a recent myelogram (which confirmed the absence of obstruction).

\section{LUMBAR CSF 5-HIAA, MHPG AND HVA} CONCENTRATIONS

The concentrations of HVA in the lumbar CSF were lower in the six patients who had obstruction of the CSF pathways than in those with no CSF obstruction $(t=4.2 ; \mathrm{P}<0.001$, Fig. 1$)$

The 5-HIAA concentrations in the lumbar CSF were lower in the patients with spinal lesions than in the 'controls' $(t=7.1 ; \mathrm{P}<0.001)$. The lumbar CSF 5-HIAA may apparently fall to low levels within 18 days of a complete spinal lesion (case 7). The 5-HIAA concentrations in the patients with 'virtually complete' lesions were not significantly higher than those with complete lesions. Obstruction of the CSF pathways had no apparent effect on the concentrations of 5-HIAA in lumbar CSF.

The MHPG concentrations in the lumbar CSF were also lower in the patients with spinal lesions compared with controls $(t=3.5 ; \mathrm{P}<0.01)$. This may apparently occur within 18 days after a complete spinal lesion (case 7). The MHPG concentration in the patients with spinal lesions appeared to be related to the segmental level of the lesion $(r=0.88 ; \mathrm{P}<0.001)$ (Fig. 2). This could reflect the activity of noradrenergic terminals in the neighbouring, spared, segments above the low thoracic or lumbar lesion, but the lesions at low segmental levels also tended to be incomplete. Cases 2 and 12 had 'virtually complete' as opposed to 'complete' lesions and therefore could have had preservation of certain (noradrenergic) long tracts. Case 9, however, also had an incomplete

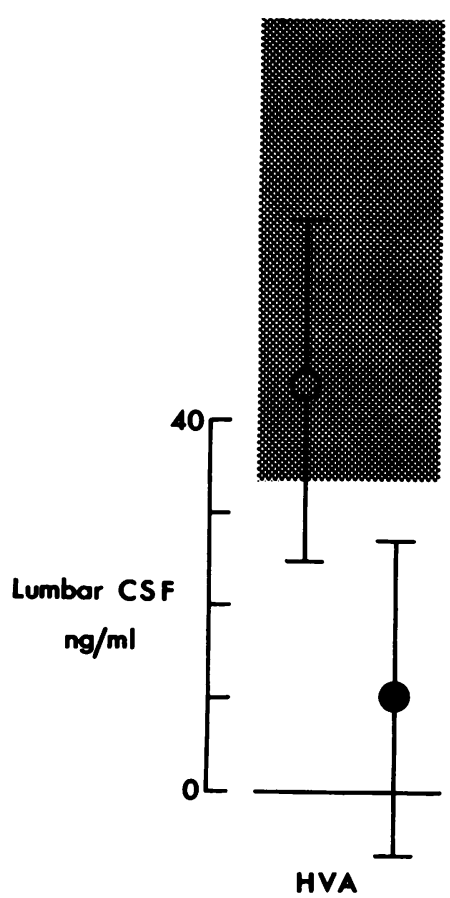

FIG. 1 Concentrations of monoamine metabolites in the lumbar CSF of 12 patients with complete or virtually complete spinal lesions (means $\pm 1 S D$ ). Transverse lesions of the spinal cord are associated with a reduction in the lumbar CSF concentrations of MHPG and 5-HIAA. Lumbar CSF HVA concentrations are reduced only in those patients with obstruction of CSF pathways. (Stippled areas represent the control means $\pm 1 S D$.) 


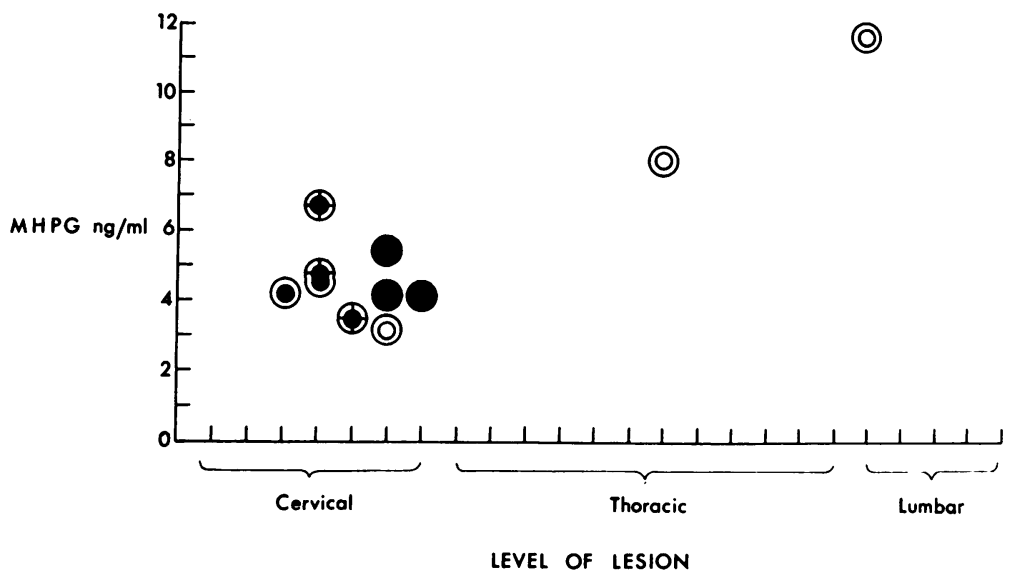

FIG. 2 Lumbar CSF MHPG concentrations plotted against the segmental level of the spinal lesion. Patients with low lesions appear to have higher concentrations of MHPG. This could reflect the presence of neighbouring functioning segments but in the patients with low lesions the lesion was more likely to be incomplete. Symbols: the central circle represents the spinal cord, the outer circle the subarachnoid space. A CSF protein of more than $0.5 \mathrm{~g} / \mathrm{l}$ and a pressure rise of less than $30 \mathrm{~mm}$ of water during the Queckenstedt test was considered to indicate definite obstruction of the CSF pathways, a raised protein alone probable obstruction. ()) Incomplete spinal lesion. No CSF block. - Complete spinal lesion. No CSF block. Complete spinal lesion. Probable CSF block. Complete spinal lesion. Definite CSF block.

lesion, but the lumbar CSF MHPG concentration was low. Obstruction of CSF pathways has no apparent effect on the levels of MHPG in lumbar CSF.

RELATIONSHIP BETWEEN SPINAL REFLEX ACTIVITY AND NEUROTRANSMITTER METABOLITES IN LUMBAR CSF

Patients who had a TVR tended to have higher levels of MHPG in the lumbar CSF (Table). Although this raises the possibility that the TVR might depend on the integrity of a descending noradrenergic pathway, the patients who had incomplete lesions (and who therefore had a TVR) tended to be those with low lesions (and therefore those with higher lumbar CSF MHPG concentrations).

Patients with low lumbar CSF HVA tended to have low $\mathbf{H}$ vibration/ $\mathbf{H}$ control ratios. This included the patients with longstanding lesions who had (unexpectedly) low $\mathrm{H}$ vibration/ $\mathrm{H}$ control ratios. In the patients with complete spinal lesions this relationship reaches statistical significance $(r=0.77 ; \mathrm{P}<0.05)$ (Fig. 3).

As there is a relationship between obstruction of CSF pathways and CSF HVA concentration it was not surprising to find that patients with obstruction of CSF pathways had lower $\mathrm{H}$ vibration/H control ratios $(t=2.7 ; \mathrm{P}<0.025)$. The $\mathrm{ATR} / \mathrm{M}$ ratios were higher $(t=3.2 ; \mathrm{P}<0.02)$ in patients with obstruction of CSF pathways.

\section{DISCUSSION}

Certain precautions are advised if the estimation of neurotransmitter metabolites in lumbar CSF is to ke meaningful. The concentrations of these amines in CSF obtained by lumbar puncture may be affected by diet (Eccleston et al., 1970), previous exercise (Post et al., 1973b), body temperature (Isaac, 1973), volume of fluid extracted (Johansson and Roos, 1975; Siever et al., 1975; Sjöström et al., 1975), position at the time of the lumbar puncture and factors which permit mixing of CSF (Siever et al., 1975), as well as by age (Gottfries et al., 1971) and by a variety of metabolic or structural lesions of the nervous system (Moskowitz and Wurtman, 1975).

An attempt was made to control all these factors in the patients with spinal lesions. Particular care was taken to avoid intermixing of CSF in the hope that CSF monoamine metabolites would, thereby, be more likely to reflect monoamine metabolites of 


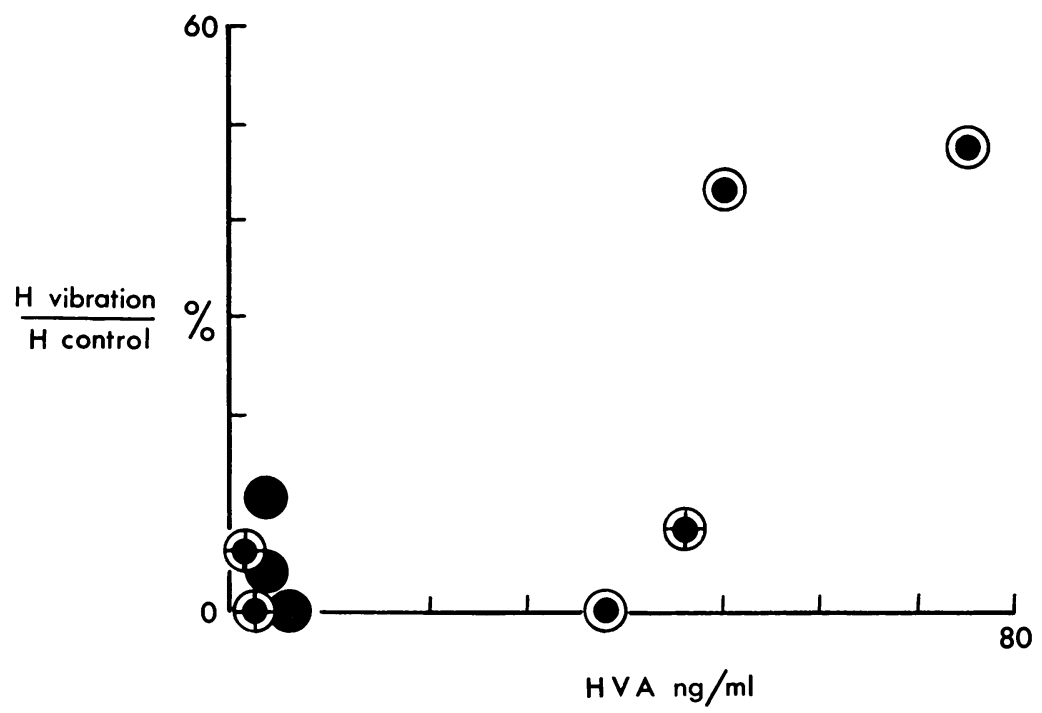

FIG. 3 Apparent relationship between low lumbar CSF HVA concentrations and enhanced activity of a spinal inhibitory mechanism (measured by the degree of inhibition of the $H$ reflex by vibration) in patients with complete spinal lesions $(r=0.77 ; \mathrm{P}<0.05)$. Symbols as for Fig. 2.

spinal origin. A Queckenstedt test had to be performed to establish whether there was any obstruction to the CSF pathways. As removal of CSF can affect the CSF pressures, this test was performed before the samples of CSF were taken. The Queckenstedt test involves some movement of CSF which could have resulted in mixing. However, displacement of CSF into the manometer is estimated to be less than $0.2 \mathrm{ml}$ for an alteration in pressure reading of $100 \mathrm{~mm} \mathrm{H}_{2} \mathrm{O}$, so this mixing effect is likely to be small. A constant volume of CSF was collected whenever possible to reduce variation resulting from the known gradient (approximately $1 \mathrm{ng} / \mathrm{ml}$ ) in the concentrations of some CSF amines (Johansson and Roos, 1975; Siever et al., 1975; Sjöström et al., 1975). The three day preparatory period and the manner in which the CSF was obtained was identical in all 12 patients so comparisons within the group can be made. The 'control' CSF, came from a miscellaneous group of patients (mostly those undergoing myelography for symptoms of disc disease). These patients did not have the same preparatory period and may have had a different level of exercise from the patients with spinal lesions (although many of the spinal patients were receiving vigorous physiotherapy and some of the 'controls' had been confined to bed for their disc symptoms). The position at the time of the lumbar puncture and volume of CSF collected was similar for both groups.

In agreement with previous reports (Post et al., 1973a; Garelis and Sourkes, 1973; Johansson and Roos, 1974) obstruction of spinal CSF pathways had little effect on lumbar CSF concentrations of 5-HIAA, suggesting that these concentrations in CSF may reflect local spinal cord 5HT metabolism. CSF 5-HIAA concentrations are higher in cisternal than in lumbar CSF (Garelis and Sourkes, 1973; Johansson and Roos, 1975; Sjöström et al., 1975), so it is evident that higher centres may make some contribution to 5-HIAA concentrations in lumbar CSF, especially if CSF mixing occurs. This contribution could explain the reduction in lumbar CSF 5-HIAA below a CSF block reported in one study (Curzon et al., 1971). Garelis et al. (1974), however, have suggested that, with minimal movements before lumbar puncture (as in the present study), it is uncertain if there is any appreciable brain contribution to the 5-HIAA concentration in lumbar CSF.

The lumbar CSF concentration of 5-HIAA appears to be reduced by a transverse spinal lesion. This was observed by Johansson and Roos (1974), although it was not demonstrated in the study of Post et al. (1973a). Spinal transection in the experimental animal reduces both spinal cord serotonin and lumbar CSF 5-HIAA (Magnusson, 1973; Bulat et al., 1974). The findings of the present study, therefore, are in keeping with the concept that serotonergic terminals in the spinal cord arise from supraspinal neurones (Dahlström and Fuxe, 1965) and suggest that de- 
generation of these terminals can occur within 18 days of a spinal lesion in man.

The MHPG concentrations in lumbar CSF in the present study were not affected by obstruction of the CSF pathways. This is in keeping with the suggestion that lumbar CSF MHPG may reflect the activity of spinal noradrenergic terminals (Chase et al., 1973; Post et al., 1973a). MHPG levels were reduced after spinal transection. This is similar to the findings of Post et al. (1973a) and in keeping with the concept that the noradrenergic terminals in the spinal cord arise from neurones in the brain stem (Dahlström and Fuxe, 1965; Magnusson, 1973). Degeneration of these terminals may evidently occur within 18 days of a spinal lesion in man. The MHPG concentration appeared to be related to the level of the lesion. The higher MHPG levels in the CSF of patients with low thoracic or lumbar lesions could represent activity of noradrenergic terminals in the neighbouring intact cord. As the lesion at low segmental levels also tended to be incomplete it could be suggested that some of the descending axons of noradrenergic neurones were preserved.

Transverse lesions of the spinal cord do not affect lumbar CSF HVA. The concentrations of HVA in lumbar CSF are reduced, however, when there is obstruction of the CSF pathways. These findings are similar to those reported previously (Curzon et al., 1971; Post et al., 1973a; Garelis and Sourkes, 1973; Johansson and Roos, 1974) and are to be expected if HVA in human CSF arises largely from the brain, probably from structures adjacent to the lateral ventricle (Garelis and Sourkes, 1973; Curzon, 1975).

The purpose of this study was to explore any possible relationships between the activity in segmental reflex pathways and neurotransmitter metabolites. It was disappointing not to find associations that could be directly related to the findings in experimental animals. For example, no relationship could be demonstrated between lumbar CSF 5-HIAA and the excitability of the monosynaptic reflex, fusimotor drive or the TVR, all of which are enhanced by 5HT in the cat (Andén et al., 1964b; Ahlman et al., 1971; Ellaway and Trott, 1975b) or between lumbar CSF MHPG and fusimotor drive which is considered to be facilitated by noradrenaline (Ellaway and Pascoe, 1969; Grillner, 1969; Phillips et al., 1973). Such relationships might become apparent in a larger series. The present study does not exclude them and should not discourage further attempts to find them. Two possible associations, however, are suggested by the present data.

MHPG levels tended to be higher in patients in whom a TVR could be obtained. These patients tended to have lesions at a lower segmental level and the higher MHPG concentrations may simply reflect the presence of neighbouring intact spinal cord in these patients. However, the descending (ventral) noradrenergic pathway in the cat is known to modulate spinal reflexes in such a way as to favour more physiological long latency polysynaptic pathways (Andén et al., 1966b) and the TVR requires facilitation of a (ventral) bulbospinal pathway in the cat (Gillies et al., 1971). This suggested association could only be confirmed by the examination of a larger series of patients with complete and incomplete lesions at the same segmental level.

There appeared to be a relationship (in patients with complete spinal lesions) between the concentrations of HVA in lumbar CSF and the degree of vibratory inhibition of the monosynaptic reflex. Muscle vibration is considered to engage a spinal inhibitory mechanism (possibly presynaptic inhibition of Ia afferent fibres). This inhibition is exaggerated immediately after a spinal lesion in man but may become less effective when 'spasticity' develops (Delwaide, 1973; Ashby and Verrier, 1975).

Three explanations for this unexpected finding mayc be considered:

1. The association could be simply a chance occur rence that would not hold true when a larger group iso $\overrightarrow{0}$ examined. Against this is the finding that those patients with longstanding lesions who had un- $\frac{\mathbb{D}}{2}$ expectedly low $\mathrm{H}$ vibration/H control ratios also had low CSF HVA.

2. The CSF HVA could represent the activity of spinal dopaminergic terminals capable of modulating this inhibitory mechanism. Dopamine can be detectedo in the spinal cord although estimates of its concentration have shown considerable variation (Hedeman $e t$ al., 1974). It has been suggested that the dopamine found in the spinal cord is not simply a precursor of noradrenaline but that it has an independent physiological role (Baker and Anderson, 1970; Magnusson, 1973). However, in the present study the overwhelming effect of obstruction of CSF pathways on CSF HVA makes it unlikely that the reflex changes can be related to the spinal release of dopamine.

3. A third possible explanation is that the obstruction of the CSF pathways in some way accounts for both the reduction in CSF HVA and the reflex changes. It is conceivable that obstruction of CSF flow or the consequent alterations in the absorption of protein or other metabolites could lead to structural changes (such as cyst formation) or modification of the plastic changes which follow spinal transection (McCouch et al., 1958) and in this way alter spinal reflexes. Obstruction of CSF pathways accompanying a spinal lesion, however, is not usually considered to be associated with any recognisable clinical effects.

In conclusion, this study confirms that spinal lesions in man are followed by substantial alterations 
in the lumbar CSF concentrations of monoamine metabolites that can probably be related to the degeneration of spinal terminals of descending axons. Certain associations between neurotransmitters and spinal reflexes are suggested.

The authors are grateful to Dr S. M. Dinsdale, Chedoke-McMaster Centre, Dr J. M. Houston, St Michael's Hospital, and to the dieticians and nursing staff of these hospitals and of the Toronto Western Hospital for their help in carrying out the study. The manuscript was prepared by Mrs E. Bailey. The illustrations were photographed by the Audio-Visual Department of the Toronto Western Hospital. Professor T. L. Sourkes provided invaluable advice.

\section{REFERENCES}

Ahlman, H., Grillner, S., and Udo, M. (1971). The effect of 5HTP on the static fusimotor activity and the tonic stretch reflex of an extensor muscle. Brain Research, 27, 393-396.

Andén, N-E. (1965). Distribution of monoamines and dihydroxy-phenylalanine decarboxylase activity in the spinal cord. Acta Physiologica Scandinavica, 64, 197-203.

Andén, N-E., Jukes, M. G. M., Lundberg, A., and Vyklický, L. (1964a). A new spinal flexor reflex. Nature, 202, 1344-1345.

Andén, N-E., Jukes, M. G. M., and Lundberg, A. (1964b). Spinal reflexes and monoamine liberation. Nature, 202, $1222-1223$

Andén, N-E., Jukes, M. G. M., and Lundberg, A. (1966a). The effect of DOPA on the spinal cord. 2. A pharmacological analysis. Acta Physiologica Scandinavica, 67, 387-397.

Andén, N-E., Jukes, M. G. M., Lundberg, A., and Vyklický, L. (1966b). The effect of DOPA on the spinal cord. 1. The influence on transmission from primary afferents. Acta Physiologica Scandinavica, 67, 373-386.

Andén, N-E., Jukes, M. G. M., Lundberg, A., and Vyklický, L. (1966c). The effect of DOPA on the spinal cord. 3. Depolarization evoked in the central terminals of ipselateral Ia afferents by volleys in the flexor reflex afferents. Acta Physiologica Scandinavica, 68, 322-336.

Anderson, E. G. (1972). Bulbospinal serotonin containing neurons and motor control. Federation Proceedings, 31, 107-112.

Ashby, P., and Verrier, M. (1975). Neurophysiological changes following spinal cord lesions in man. Canadian Journal of Neurological Sciences, 2, 91-100.

Baker, R. G., and Anderson, E. G. (1970). The effects of L-3,4-dihydroxy-phenylalanine on spinal reflex activity. Journal of Pharmacology and Experimental Therapeutics, 173, 212-223.

Bergmans, J., and Grillner, S. (1969). Reciprocal control of spontaneous activity and reflex effects in static and dynamic flexor gamma motoneurones revealed by an injection of DOPA. Acta Physiologica Scandinavica, 77, 106-124.

Bond, P. A. (1972). The determination of 4-hydroxy-3methoxy phenylethylene glycol in urine and CSF using gas chromatography. Biochemical Medicine, 6, 36-45.

Bulat, M., Lacković, Z., Jakupčevič, M., and Damjanov, I. (1974). 5-hydroxyindoleacetic acid in the lumbar fluid: A specific indicator of spinal cord injury. Science, 185, 527-528.

Chase, T. N., Gordon, E. K., and Ng, L. K. Y. (1973). Norepinephrine metabolism in the central nervous system of man: studies using 3-methoxy-4-hydroxyphenylethylene glycol levels in cerebrospinal fluid. Journal of Neurochemistry, 21, 581-587.

Curzon, G. (1975). CSF homovanillic acid: an index of dopaminergic activity. In Advances in Neurology, vol. 9, pp. 349-357. Edited by D. B. Calne, T. N. Chase, and A. Barbeau. Raven Press: New York.

Curzon, G., Gumpert, E. J. W., and Sharpe, D. M. (1971). Amine metabolites in the lumbar cerebrospinal fluid of humans with restricted flow of cerebrospinal fluid. Nature New Biology, 231, 189-191.

Dahlström, A., and Fuxe, K. (1965). Evidence for the existence of monoamine neurons in the central nervous system. 2. Experimentally induced changes in the intraneuronal amine levels of bulbospinal neuron systems. Acta Physiologica Scandinavica, 64, suppl. 247, 1-36.

Delwaide, P. J. (1973). Human monosynaptic reflexes and presynaptic inhibition. An interpretation of spastic hyperreflexia. In New Developments in Electromyography and Clinical Neurophysiology, vol. 3, pp. 508-522. Edited by J. E. Desmedt. Karger: Basel.

Dietrichson, P. (1973). The role of the fusimotor system in spasticity and parkinsonian rigidity. In New Developments in Electromyography and Clinical Neurophysiology, vol. 3, pp. 496-507. Edited by J. E. Desmedt. Karger: Basel.

Eccleston, D., Ashcroft, G. W., Crawford, T. B. B., Stanton, J. B., Wood, D., and McTurk, P. H. (1970). Effect of tryptophan administration on 5HIAA in cerebrospinal fluid in man. Journal of Neurology, Neurosurgery, and Psychiatry, 33, 269-272.

Ellaway, P. H., and Pascoe, J. E. (1968). Noradrenaline as a transmitter in the spinal cord. Journal of Physiology, 197, 8-9P.

Ellaway, P. H., and Trott, J. R. (1975a). The mode of action of 5-hydroxytryptophan in facilitating a stretch reflex in the spinal cat. Experimental Brain Research, 22, $145-162$.

Ellaway, P. H., and Trott, J. R. (1975b). Facilitation of the tonic vibration reflex in the spinal cat by 5-hydroxytryptophan. Journal of Physiology, 249, 54-56P.

Garelis, E., and Sourkes, T. L. (1973). Sites of origin in the central nervous system of monoamine metabolites measured in human cerebrospinal fluid. Journal of Neurology, Neurosurgery, and Psychiatry, 36, 625-629. 
Garelis, E., Young, S. N., Lal, S., and Sourkes, T. L. (1974). Monoamine metabolites in lumbar CSF: the question of their origin in relation to clinical studies. Brain Research, 79, 1-8.

Giacalone, E., and Valzelli, L. (1966). A method for the determination of 5-hydroxyindol-3-acetic acid in brain. Journal of Neurochemistry, 13, 1265-1266.

Gillies, J. D., Burke, D. J., and Lance, J. W. (1971). Tonic vibration reflex in the cat. Journal of Neurophysiology, 34, 252-262.

Gordon, E. K., Oliver, J., Black, K., and Kopin, I. J. (1974). Simultaneous assay by mass fragmentography of vanillylmandelic acid, homovanillic acid, and 3methoxy-4-hydroxy-phenethylene glycol in cerebrospinal fluid and urine. Biochemical Medicine, 11, 32-40.

Gottfries, C. G., Gottfries, I., Johansson, B., Olsson, R., Persson, T., Roos, B-E., and Sjöström, R. (1971). Acid monoamine metabolites in human cerebrospinal fluid and their relations to age and sex. Neuropharmacology, 10, 665-672.

Grillner, S. (1969). The influence of DOPA on the static and the dynamic fusimotor activity to the triceps surae of the spinal cat. Acta Physiologica Scandinavica, 77, 490-509.

Grillner, S. (1973). Locomotion in the spinal cat. In Control of Posture and Locomotion, pp. 515-535. Edited by R. B. Stein, K. G. Pearson, R. S. Smith, and J. B. Redford. Plenum Press: New York.

Hedeman, L. S., Shellenberger, M. K., and Gordon, J. H. (1974). Studies in experimental spinal cord trauma. I. Alterations in catecholamine levels. Journal of Neurosurgery, 40, 37-43.

Hillarp, N-Å., Fuxe, K., and Dahlström, A. (1966). Demonstration and mapping of central neurons containing dopamine, noradrenaline, and 5-hydroxytryptamine and their reactions to psychopharmaca. Pharmacological Reviews, 18, 727-740.

Isaac, L. (1973). Temperature alteration of monoamine metabolites in cerebrospinal fluid. Nature New Biology, 243, 269-271.

Johansson, B., and Roos, B-E. (1974). 5-hydroxyindolacetic acid and homovanillic acid in cerebrospinal fluid of patients with neurological diseases. European Neurology, 11, 37-45.

Johansson, B., and Roos, B-E. (1975). Concentrations of monoamine metabolites in human lumbar and cisternal cerebrospinal fluid. Acta Neurologica Scandinavica, 52, 137-144.

Jurna, I., and Lundberg, A. (1968). The influence of an inhibitor of dopamine-beta-hydroxylase on the effect of DOPA on transmission in the spinal cord. In Structure and Function of Inhibitory Mechanisms, pp. 469-472. Edited by C. Von Euler, S. Skoglund, and V. Soderberg. Pergamon Press: New York.

Lance, J. W., Burke, D., and Andrews, C. J. (1973). The reflex effects of muscle vibration. Studies of tendon jerk irradiation, phasic reflex inhibition and the tonic vibration reflex. In New Developments in Electromyography and Clinical Neurophysiology, vol. 3, pp. 444-462. Edited by J. E. Desmedt. Karger: Basel.

Lloyd, K. G., Farley, I. J., Deck, J. H. N., and Hornykiewicz, O. (1974). Serotonin and 5-hydroxyindoleacetic acid in discrete areas of the brainstem of suicide victims and control patients. In Advances in Biochemical Psychopharmacology, vol. 11, pp. 387-397. Raven Press: New York.

McCouch, G. P., Austin, G. M., Liu, C. N., and Liu, C. Y. (1958). Sprouting as a cause of spasticity. Journal of Neurophysiology, 21, 205-216.

Magnusson, T. (1973). Effect of chronic transection on dopamine, noradrenaline and 5-hydroxytryptamine in the rat spinal cord. Naunyn-Schmiedeberg's Archives of Pharmacology, 278, 13-22.

Meulemans, O. (1960). Determination of total protein in spinal fluid with sulphosalicylic acid and trichloroacetic acid. Clinica Chimica Acta, 5, 757-761.

Moskowitz, M. A., and Wurtman, R. J. (1975). Catecholamines and neurological disease. New England Journal of Medicine, 293, 274-280, and 332-338.

Nobin, A., and Björklund, A. (1973). Topography of the monoamine neuron systems in the human brain ase $\vec{N}$ revealed in fetuses. Acta Physiologica Scandinavica, suppl. 388, 1-40.

Olson, L., Nyström, B., and Seiger, Å. (1973). Monoamine fluorescence histochemistry of human post mortem brain. Brain Research, 63, 231-247.

Phillips, S. J., Richens, A., and Shand, D. G. (1973) Adrenergic control of tendon jerk reflexes in man British Journal of Pharmacology, 47, 595-605.

Post, R. M., Goodwin, F. K., Gordon, E., and Watkino D. M. (1973a). Amine metabolites in human cerebrospinal fluid: effects of cord transection and spinal fluid block. Science, 179, 897-899.

Post, R. M., Kotin, J., Goodwin, F. K., and Gordon, E. K. (1973b). Psychomotor activity and cerebrospinal fluid amine metabolites in affective illness. American Journal of Psychiatry, 130, 67-72.

Siever, L., Kraemer, H., Sack, R., Angwin, P., Berger, P., Zarcone, V., Barchas, J., and Brodie, K. H. (1975). Gradients of biogenic amine metabolites in cerebrospinal fluid. Diseases of the Nervous System, 36, 13-16.

Sjöström, R., Ekstedt, J., and Ånggård, E. (1975). Concentration gradients of monoamine metabolites in human cerebrospinal fluid. Journal of Neurology, Neurosurgery, and Psychiatry, 38, 666-668.

Watson, E., Wilk, S., and Roboz, J. (1974). Derivatization and gas chromatographic determination of some biologically important acids in cerebrospinal fluid. Analytical Biochemistry, 59, 441-451.

Weaver, R. A., Landau, W. M., and Higgins, J. F. (1963). Fusimotor function. Part 2. Evidence of fusimotor depression in human spinal shock. Archives of Neurology (Chic.), 9, 127-132. 